\title{
La cuestión eco-social: notas para un debate contemporáneo en ciencias sociales
}

\author{
Rossana Ciorino N.
}

\author{
RESUMEN:
}

En el contexto del actual proceso de desarrollo chileno, se manifiestan tensiones entre Economía, Estado y Bienestar Social-ambiental, dando origen a lo que denominaremos "cuestión eco-social", término que no es más que la expresión equivalente a la desorganización eco-sistémica de los sistemas productivos que, guiados por la lógica tecnológica y del mercado, han generado un conjunto de problemas sociales con contenido ambiental, derivados de la puesta en práctica del paradigma económico depredador y excluyente, administrado por un Estado Neoliberal desde hace más de tres décadas en Chile, generando un deficiente bienestar en lo social y ambiental. El objetivo de este trabajo, es aportar al debate contemporáneo sobre la cuestión eco-social, que se manifiesta como un conjunto de conflictos socio-ambientales en comunidades a lo largo de las regiones del país, configurándose nuevas demandas ciudadanas en cuanto a derechos ambientales. De allí que se hace necesario aportar a la formación de una nueva racionalidad social en los estudiantes de las ciencias sociales (incluyendo al Trabajo Social) que les permita problematizar la lógica del paradigma económico dominante, en pos de lograr la transición hacia un desarrollo sustentable y democrático que supere la confrontación entre las dos racionalidades: económica versus ambiental.

Palabras clave: Cuestión eco-social - Conflictos socio-ambientales Racionalidad ambiental - Saber ambiental - Ciencias sociales.

\section{A questão eco-social: notas para um debate contemporâneo em Ciências Sociais}

\section{RESUMEM}

No contexto do atual processo de desenvolvimento chileno, se manifestam tensões entre Economia, Estado e Bem-estar Social - ambiental, dando origem ao que denominaremos "questão eco - social", término que no é mais que a expressão equivalente à desorganização eco sistêmica dos sistemas produtivos que, guiados pela lógica tecnológica e do mercado, tem gerado

* Chilena. Asistente Social Universidad de Chile. Magíster (c) en Historia y Ciencias Sociales, Universidad ARCIS. Docente Universidad Católica Silva Henríquez. Coordina Proyecto Lideresas por el Desarrollo sustentable (ONG Tierra Nuestra). Correo electrónico: iciorinon@ucsh.cl 
um conjunto de problemas sociais com conteúdo ambiental, derivados do início da prática do paradigma econômico depredador e excludente, administrado por um Estado Neoliberal desde ha mais de três décadas no Chile, gerando um deficiente bem-estar no social e ambiental. O objetivo deste trabalho é aportar ao debate contemporâneo sobre a questão eco social, que se manifesta como um conjunto de conflitos socioambientais em comunidades ao longo das regiões do país, se configurando novas demandas cidadãs em quanto a direitos ambientais. Desde então que se faz necessário aportar á formação de uma nova racionalidade social nos estudantes das ciências sociais (incluindo ao Trabalho Social) que permita problematizar a lógica do paradigma econômico dominante, em pós de lograr a transição a um desenvolvimento sustentável e democrático que supere a confrontação entre as duas racionalidades: econômica versus ambiental.

Palavras chave: Questão eco-social - Conflitos socioambientais Racionalidade ambiental - Saber ambiental - Ciências sociais.

\section{The eco-social question: notes for a contemporary debate in social sciences}

\section{ABSTRACT}

In the current development process in Chile, there exist tensions among the economic system, the State, and environmental social welfare which give rise to what we call "the eco-social question". This term refers to the eco-systemic disorganisation of productive systems which following market-driven technological logics has created environmental social problems. These problems come from the implementation of an excluding and destroying economic paradigm by the neoliberal Chilean State in the last three decades which causes unsatisfactory social and environmental welfare. This work attempts to contribute to the contemporary debate on the eco-social question as those socio-environmental conflicts within communities in the different regions of the country. These conflicts organise new civic requests related to environmental rights and thus it is important to contribute towards new forms of social rationality among social sciences students (including social work students). These new forms of rationality may allow students to question the logics of the dominating economic paradigm in order to reach a democratic and sustainable development that goes beyond the traditional dichotomy between economic logics versus environmental ones.

Key words: eco-social question - socio-environmental conflicts environmental rationality - environmental knowledge - social sciences 


\section{Introducción}

El presente artículo surge de una reflexión de la práctica docente en temáticas de Ecología, y Sustentabilidad, desarrolladas en la Universidad Católica Silva Henríquez, dirigida a estudiantes de diversas disciplinas de la Facultad de Ciencias Sociales, Jurídicas y Económicas (Trabajo Social, Psicología, Sociología, Economía y Derecho), entre los años 2009-2013. Además, se suma a ello, la experiencia como educadora socio-ambiental en proyectos de formación destinados a mujeres lideresas de diversas organizaciones sociales/culturales/ambientales de sectores populares en dos comunas de la zona sur de Santiago: Lo Espejo y La Pintana. Ambas experiencias tienen, como conducta de entrada del aprendizaje, la cuestión eco-social a nivel nacional y global. En dichos procesos educativos se constató con los participantes que este saber ambiental es débilmente conocido. A nivel de educación superior, no existe una reflexión transversal en las mallas curriculares respecto a los impactos sociales que tiene la crisis ecológica, así como también se aprecia una debilidad en cuanto al debate interdisciplinario en torno a la cuestión ambiental. Incluso se constata una reflexión deficitaria en torno al rol del científico social con relación a su doble función: por un lado, en tanto productor de conocimiento; por otro, respecto al rol de las profesiones sociales en el campo de la intervención social en conflictos socio-ambientales.

Se parte de la premisa de que el origen de los problemas ambientales nacionales reside, por una parte, en la puesta en práctica de una racionalidad económica basada en el manejo macroeconómico del desarrollo, cuya consolidación ha sido resultado de la externalización de los costos "sociales" y "ambientales" de los procesos productivos, privilegiando la competitividad exportadora en desmedro de las externalidades negativas que impactan la calidad de vida de las personas y comunidades, que no han detenido el deterioro ecológico ni social del país. De otra, y simultáneamente a ello, existe una tendencia de apropiación de los recursos naturales por parte del capital global que ha agravado la crisis ambiental nacional. A partir de este escenario nos preguntarnos por la relación que tienen estos problemas socio-ambientales con los fundamentos del modo de producción y reproducción capitalista.

En las últimas décadas, en nuestro país, se ha venido configurando una nueva cultura ecológica y un impulso democratizador 
asociado a los objetivos y demandas de múltiples movimientos sociales, cuyo horizonte es la utopía de lograr un desarrollo más sustentable en lo económico, social y ambiental. Dicha utopía, se logrará en la medida que la actual sociedad chilena, ícono de una sociedad desigual y mercado-céntrica, vaya superando las brechas de inequidad existentes, así como también modificando ciertos patrones de producción y de consumo que ponen en riesgo la sobrevivencia de las presentes y futuras generaciones, en pos de lograr un mayor bienestar social y ambiental ${ }^{1}$ para nuestro país.

Sin embargo, es la población más vulnerable la que asume dichas externalidades negativas, tanto en lo social como en lo ambiental, produciéndose injusticias en ambos campos de ciudadanía. En la dimensión social del bienestar, la inequidad en Chile está directamente relacionada con la acumulación de capitales, donde un $1 \%$ de los chilenos percibe un promedio de ingreso per cápita mensual de 180 mil dólares (100 millones de pesos chilenos) a diferencia del porcentaje restante que percibe un ingreso per cápita promedio equivalente a US\$ 720 dólares mensuales (\$350.000 chilenos).

En la dimensión ambiental, producto de que el Estado chileno ha traspasado a la iniciativa privada (nacional y transnacional) la explotación, uso y gestión de los servicios ambientales, tales como agua, energía, carbono, cobre, conservación de bienes naturales y tierras, entre otros, podemos observar que esta tendencia nos ha llevado a una apropiación desmedida de los recursos naturales por parte de las empresas transnacionales, persistiendo la importancia dada a las exportaciones de materias primas, al sector privado y a la inversión extranjera. El ejemplo más escandaloso es el caso de los recursos hídricos. Debido a la vigencia del Código de Aguas heredado de la dictadura desde 1981, que permite la apropiación y la especulación con los recursos hídricos y concesiones de derechos de agua, gratuitos y a perpetuidad a las transnacionales, en el año 2011

1 Bienestar social: Estado o sensación subjetiva y objetiva de bienestar que experimenta una población, por tener acceso a satisfactores de calidad que le permiten satisfacer de forma oportuna las necesidades de subsistencia y protección (alimentación, salud, vivienda, previsión, aire, agua, entre otras) que le brindan mayor calidad de vida.

Bienestar ambiental: Estado o sensación subjetiva y objetiva de bienestar que experimenta una población por tener acceso a servicios ambientales y/o recursos naturales que le permiten satisfacer de forma oportuna las necesidades ecológicas para la vida (individual y colectiva) en igualdad de condiciones, que garantizan un desarrollo en equilibrio con el medio ambiente. 
la Corporación de Fomento de la producción (CORFO) vendió cerca del $30 \%$ de su propiedad a la empresa sanitaria Aguas Andina $^{2}$, recaudando alrededor de US\$1.000 millones en la transacción bursátil. Hoy sólo mantiene el 5\% de las acciones. De las empresas sanitarias que funcionan en el país, el 100\% está en manos de transnacionales ${ }^{3}$. Es el caso de la española Endesa, que domina el campo de la generación de electricidad, siendo la mayor poseedora de derechos de aguas para uso no consuntivo, o sea, centrales hidroeléctricas (Larraín, 2010: 18).

El proceso de desarrollo actual tensiona las relaciones entre Economía Neoliberal, Estado y Bienestar socio-ambiental, entendido éste como aquel bienestar donde todas las personas o comunidades acceden de manera equitativa y justa a un conjunto de bienes/servicios sociales y/o ambientales de calidad que debieran garantizar un bienestar en lo social y ambiental. Se entiende además por bienestar al conjunto de satisfactores materiales o inmateriales que una persona necesita para gozar de una buena calidad de vida.

La existencia de la racionalidad capitalista global, basada en la racionalidad tecnológica y el cálculo económico, que legitima los valores de la productividad inmediata, la ganancia y la eficiencia, han impactado negativamente el potencial ambiental del desarrollo y la calidad de vida de muchas comunidades en Chile. De allí la necesidad de dar cuenta en este artículo de las contradicciones existentes entre la racionalidad económica vigente y la racionalidad ambiental, desde cuya confrontación no resuelta surge el saber ambiental, el cual se inscribe en las formaciones ideológicas del ecologismo/ambientalismo, en los discursos de la ética de la sustentabilidad ambiental y en las prácticas de lucha de diversos movimientos sociales en pro de la preservación de los recursos naturales estratégicos para el país (agua, tierras, conservación de tierras agrícolas, recursos del mar, aire limpio, defensa de patrimonios naturales, etc.), fenómenos que han ido configurando los denominados conflictos socio-ambientales a

2 Aguas Andinas es la empresa surgida tras la privatización de EMOS en los gobiernos de Eduardo Frei y Ricardo Lagos. Sus dueños hoy son la española Agbar y la francesa Suez, más pequeños accionistas. En junio de 2011, el gobierno de Sebastián Piñera terminó de vender el 30\% del total acciones que el Estado de Chile poseía a través de la CORFO. Uno de los accionistas menores es Andrés Chadwick, ministro del Gobierno de Piñera.

3 Con excepción de SMAPA, Empresa Sanitaria Municipal de Agua Potable y Alcantarillado en la comuna de Maipú, la cual gestiona y distribuye agua potable y alcantarillado a tres comunas: Maipú, Cerrillos y Estación Central, todos de la Región Metropolitana de Santiago. 
nivel nacional. En el desarrollo de esta temática, se dará cuenta de algunas categorías de análisis tomadas del ecologismo marxista y desde la ecología política sustentada por Enrique Leff (2001) con el fin de esclarecer las diferencias entre la racionalidad económica-capitalista versus la racionalidad ambiental, para entender las tensiones entre Economía, Estado y Bienestar. Finalmente, se señalarán algunos desafíos acerca del rol que debieran jugar las ciencias sociales en la producción de nuevos conocimientos y en las prácticas de intervención en la cuestión ambiental, que posibiliten la deconstrucción del paradigma dominante, con el fin de contribuir a la emergencia de un modelo de desarrollo alternativo que brinde a las personas y comunidades mayor bienestar social-ambiental.

\section{Una mirada a la cuestión eco-social vigente}

Para describiry desentrañar los matices que hoy adquiere el debate contemporáneo sobre la "cuestión social" en Chile, debemos hacernos cargo de la historia social y ambiental nacional. La "cuestión social" de principios de siglo XX fue comprendida por diferentes sectores de la sociedad chilena, como equivalente a la "cuestión obrera" y como producto de la barbarie capitalista que sentó las bases de los procesos de industrialización en Chile a mediados del siglo XIX, cuyo modelo de desarrollo hacia afuera, viró hacia un modelo hacia adentro a partir de 1925, el cual instala una matriz Estado céntrica - industrializadora, hasta septiembre de 1973. En ese período, el Estado asumió un rol distributivo y empresarial, haciéndose cargo de "la cuestión social" mediante políticas sociales universales, solidarias, donde la protección del empleo formó parte del Estado de Bienestar Desarrollista, como eje del desarrollo social y económico.

El debate sobre la cuestión social en esa época duró entre 1860 y 1925 en Chile y tuvo como eje fundamental de discusión la primera contradicción principal: el conflicto entre capital-trabajo (Aquín, 2006), cuyas expresiones estuvieron asociadas a las malas condiciones laborales, sobreexplotación de la fuerza de trabajo, problemas de mortalidad y morbilidad del cuerpo de los pobres, viviendas insalubres, analfabetismo, entre otros. Desde el siglo XIX y principios del XX, la sociedad aún no visualizaba los costos ambientales inherentes a los procesos productivos, dejando fuera las relaciones establecidas entre el ser humano y la naturaleza en los procesos de trabajo. 
Coincidimos con Mauricio Folchi (2001), respecto al hecho de que los problemas ambientales no se iniciaron en las formaciones económicas del régimen militar, sino que éstos han existido en Chile desde mucho antes de 1974. Agrega el historiador que la dimensión ambiental no era incorporada como una variable constitutiva de los problemas sociales ni de los procesos productivos de la época. Ejemplo de esto es el uso del Asbesto en la industria manufacturera de producción de materiales de construcción (Pizarreño) que operaba en Chile desde 1935. Sólo a partir del año 2001, bajo el gobierno de Ricardo Lagos, se prohibió el uso, producción, importación, distribución, venta y uso de asbesto-cemento (decreto ley № 656), cuya legislación se hizo bajo las recomendaciones del Convenio $N^{\circ} 162$ de la OIT (Organización Internacional del Trabajo) y que fue ratificado en 1986 por el gobierno chileno. Dicha medida respondió a la denuncia pública de muchas personas afectadas por asbestosis y cáncer al pulmón que habían pertenecido a la empresa Pizarreño en la comuna de Maipú y San Pedro de la Paz (Concepción), siendo afectados trabajadores y pobladores que, por vivir dentro de un radio geográfico cercano a dicha empresa, contrajeron dichas enfermedades letales. Este problema, para algunos autores, constituye uno de los "ecocidios" industriales más grandes de la industria chilena, la cual venía utilizando el asbesto desde 1935.

Posteriormente, desde 1974 en adelante, se transitó hacia un modelo de crecimiento primario-exportador o "hacia afuera", basado en la explotación de bienes primarios -minería, pesca, agroindustria y forestal- (Quiroga, 2003:6) que acompañados de medidas privatizadoras de los servicios sociales (salud, educación, vivienda, seguridad social, entre otros) impuestas en 1981 por el régimen cívico-militar pinochetista, posibilitaron la consolidación de una sociedad mercado-céntrica, virando hacia la constitución de un Estado de Bienestar Residual ${ }^{4}$ (EspingAndersen, 1993), regido por los principios neoliberales de la competencia, el individualismo, el rol subsidiario del Estado y la focalización, como estrategia de selección de los más pobres y vulnerables merecedores de la ayuda estatal.

Sin embargo, el debate actual sobre la cuestión social, debe re-situarse en las relaciones conflictivas entre capital-trabajo-

4 Estado de Bienestar Residual: se refiere a un modo combinado e interdependiente de implementar el Bienestar Social, producido y distribuido entre el Estado, el Mercado y la familia. La obligación pública empieza sólo donde falla el mercado: la lógica de la mercantilización tiene primacía, por sobre la lógica de los derechos sociales. 
naturaleza bajo la fase neoliberal globalizada del capitalismo. Dicha tríada conceptual nos ayudará a comprender la densidad compleja que conforman los conflictos socio-ambientales actuales, puesto que los procesos productivos de la economía de exportación de materias primas y/o sectores agroindustriales, no incorporan los costos ambientales ni sociales en los costos de producción y/o de mercado, cuyos agentes económicos, tanto nacionales como transnacionales, buscan la maximización de sus ganancias, sin incorporar los impactos negativos en dichos procesos. A consecuencia de ello, son los trabajadores/ as y las comunidades las más afectadas por diversos proyectos de inversión, quienes deben asumir estos costos ambientales negativos (daño ambiental e impactos negativos en la salud de los trabajadores y/o en la comunidad), así como también los costos sociales, tales como: bajos salarios y/o flexibilidad contractual, cuyas consecuencias se evidencian con mayor fuerza hoy en la des-capitalización individual de las pensiones de las generaciones actuales y futuras, que contradicen el supuesto éxito de las Asociaciones de Fondos de Pensiones, AFP.

La crisis que hoy padecemos como sociedad nacional es multidimensional: es económica, social, política, ambiental y epistémica; es fruto de las lógicas de apropiación del sistema capitalista, que promueve una racionalidad productiva para la acumulación de capital, concentrada en pocas manos, y al mismo tiempo, se intensifica dicha acumulación, al persistir, “aún en Chile el DL 600 de 19745, que consagró una discriminación arbitraria a favor de los inversionistas extranjeros, en desmedro de los emprendedores nacionales. Con este decreto vigente, el Estado ha perdido soberanía nacional sobre sus recursos, minimizando su tributación, y resguardando el derecho de propiedad consagrado en la Constitución del 80" (Quiroga, 2003:5).

Siguiendo en la misma línea de reflexión, se constata que por el carácter oligopólico de muchas empresas chilenas y la concentración del poder en pocas manos, se ha propiciado aún más la concentración de la propiedad en diversos ámbitos de la economía. Algunos datos que confirman lo anterior, es el caso del mercado de la Educación (los dueños de las corporaciones de

5 Decreto Ley 600 o Estatuto de Inversión Extranjera. Data de agosto de 1974, sustituyó al régimen restrictivo establecido por Chile en el Pacto Andino. Dicho DL 600 fue ratificado por el Congreso Nacional en mayo 1993, introduciéndole mínimas modificaciones. Este mecanismo es el más usado por los inversionistas extranjeros. En ninguna otra economía del mundo tienen un sistema parecido, las únicas excepciones son Chile y Portugal con regímenes contractuales, donde se permite la inversión extranjera a costo cero. 
educación subvencionada y universidades privadas, corresponden a ex ministros de Educación que gobernaron bajo la Concertación y a muchos miembros de la casta política-UDI, RN, DC-y grupos económicos como, por ejemplo, los Matte). En el área pesquera, son nueve los grupos económicos que concentran el 90\% de la pesca industrial, un negocio que les reporta más de US\$1.200 millones al año (Figueroa, 2012). La casta política dirigente, durante décadas, ha apoyado a los grandes grupos económicos pesqueros para que sus capturas pasen directamente desde las bodegas de sus embarcaciones a sus fábricas de harina y aceite de pescado, destinando casi toda esta producción a la alimentación animal.

Como se expresara anteriormente, también la cuestión ecosocial implica una crisis del conocimiento (paradójicamente, en plena era del conocimiento) que, en el caso de las ciencias sociales, se observa a través de cierta resistencia a aceptar la causalidad sociológica de los problemas ambientales y a captar los procesos sociales que están en el germen de una nueva ética de la sustentabilidad, presente en los valores y acciones colectivas de los movimientos ecologistas, obstaculizando una praxis profesional orientada a la producción de conocimientos y a la generación de prácticas de intervención orientadas al apoyo de los actores ecológicos en pos de la construcción de una nueva racionalidad social y construcción de ciudadanía socioambiental.

Con el fin de de hacer más comprensible la noción de saber ambiental en tanto proceso en construcción, que opera en la praxis como una nueva fuerza productiva y una nueva fuerza política que cuestiona la destrucción de la base de los recursos de la humanidad, así como también los valores y comportamientos humanos destructores/depredadores del medio ambiente, se hace necesario a continuación presentar las diferencias entre ambas racionalidades: económica y ambiental. 


\begin{tabular}{|c|c|c|}
\hline & RACIONALIDAD ECONÓMICA & RACIONALIDAD AMBIENTAL \\
\hline $\begin{array}{l}\text { Rol de la } \\
\text { Economía }\end{array}$ & $\begin{array}{l}\text { Desarrollo equivale a } \\
\text { crecimiento económico. } \\
\text { Los sistemas ecológicos } \\
\text { y recursos naturales son } \\
\text { ilimitados. } \\
\text { Importan las tendencias } \\
\text { macroeconómicas y la } \\
\text { subordinación de las } \\
\text { economías locales a la } \\
\text { economía global. }\end{array}$ & $\begin{array}{l}\text { Desarrollo es económico, social } \\
\text { y ambiental. No es equivalente a } \\
\text { crecimiento. } \\
\text { Los sistemas ecológicos y recursos } \\
\text { naturales son limitados. } \\
\text { Importan las tendencias a escala } \\
\text { local, cuestiona la globalización de } \\
\text { los mercados. }\end{array}$ \\
\hline $\begin{array}{l}\text { Concepción de la } \\
\text { naturaleza }\end{array}$ & $\begin{array}{l}\text { La naturaleza es vista como } \\
\text { objeto a explotar. La ciencia y } \\
\text { la tecnología pueden dominarla } \\
\text { para extraer sus más preciados } \\
\text { tesoros naturales. } \\
\text { Concepción antro/andro/ } \\
\text { céntrica: la naturaleza sometida } \\
\text { al dominio de la racionalidad } \\
\text { masculina y al servicio del ser } \\
\text { humano. }\end{array}$ & $\begin{array}{l}\text { La naturaleza es vista como } \\
\text { ecosistema de vida, gestión y } \\
\text { protección del medio ambiente y la } \\
\text { biodiversidad. } \\
\text { Reapropiación sociocultural de la } \\
\text { naturaleza. }\end{array}$ \\
\hline $\begin{array}{l}\text { Racionalidad } \\
\text { científica }\end{array}$ & $\begin{array}{l}\text { La racionalidad económica ha } \\
\text { estado asociada a incrementar } \\
\text { la capacidad de control sobre } \\
\text { la naturaleza, a través de la } \\
\text { ciencia moderna, donde la } \\
\text { razón instrumental se vuelve } \\
\text { irracional, puesto que las } \\
\text { externalidades negativas } \\
\text { han engendrado sus fuerzas } \\
\text { destructivas. } \\
\text { La racionalidad científica } \\
\text { comprende un sistema } \\
\text { mundo cerrado, unipolar, } \\
\text { predeterminado, previsible, } \\
\text { e irreductible a un patrón de } \\
\text { producción y estilo de vida con } \\
\text { pretensiones hegemónicas. La } \\
\text { razón científica y tecnológica ha } \\
\text { estado al servicio del mercado. }\end{array}$ & $\begin{array}{l}\text { La racionalidad ambiental tiene } \\
\text { el propósito de internalizar las } \\
\text { externalidades negativas de los } \\
\text { procesos productivos y sobre ésta } \\
\text { subyace más bien el concepto de } \\
\text { "adaptación" a la naturaleza, más } \\
\text { que de "dominio", en que se apoya } \\
\text { la ciencia moderna. } \\
\\
\text { Plantea una racionalidad científica } \\
\text { basada en la comprensión de } \\
\text { una realidad compleja, abierta } \\
\text { a la indeterminación y a la } \\
\text { interdependencia de los procesos. }\end{array}$ \\
\hline $\begin{array}{l}\text { Papel de las } \\
\text { tecnologías }\end{array}$ & $\begin{array}{l}\text { Soluciones técnicas para } \\
\text { revertir la degradación } \\
\text { ambiental. } \\
\text { Estima que la tecnología } \\
\text { va a resolver los problemas } \\
\text { de escasez y/o problemas } \\
\text { ambientales }\end{array}$ & $\begin{array}{l}\text { Propone tecnologías limpias a } \\
\text { escala local. } \\
\text { Revalorización cultural de } \\
\text { tecnologías ancestrales. Patrones } \\
\text { tecnológicos que no deterioren el } \\
\text { medio ambiente. }\end{array}$ \\
\hline
\end{tabular}




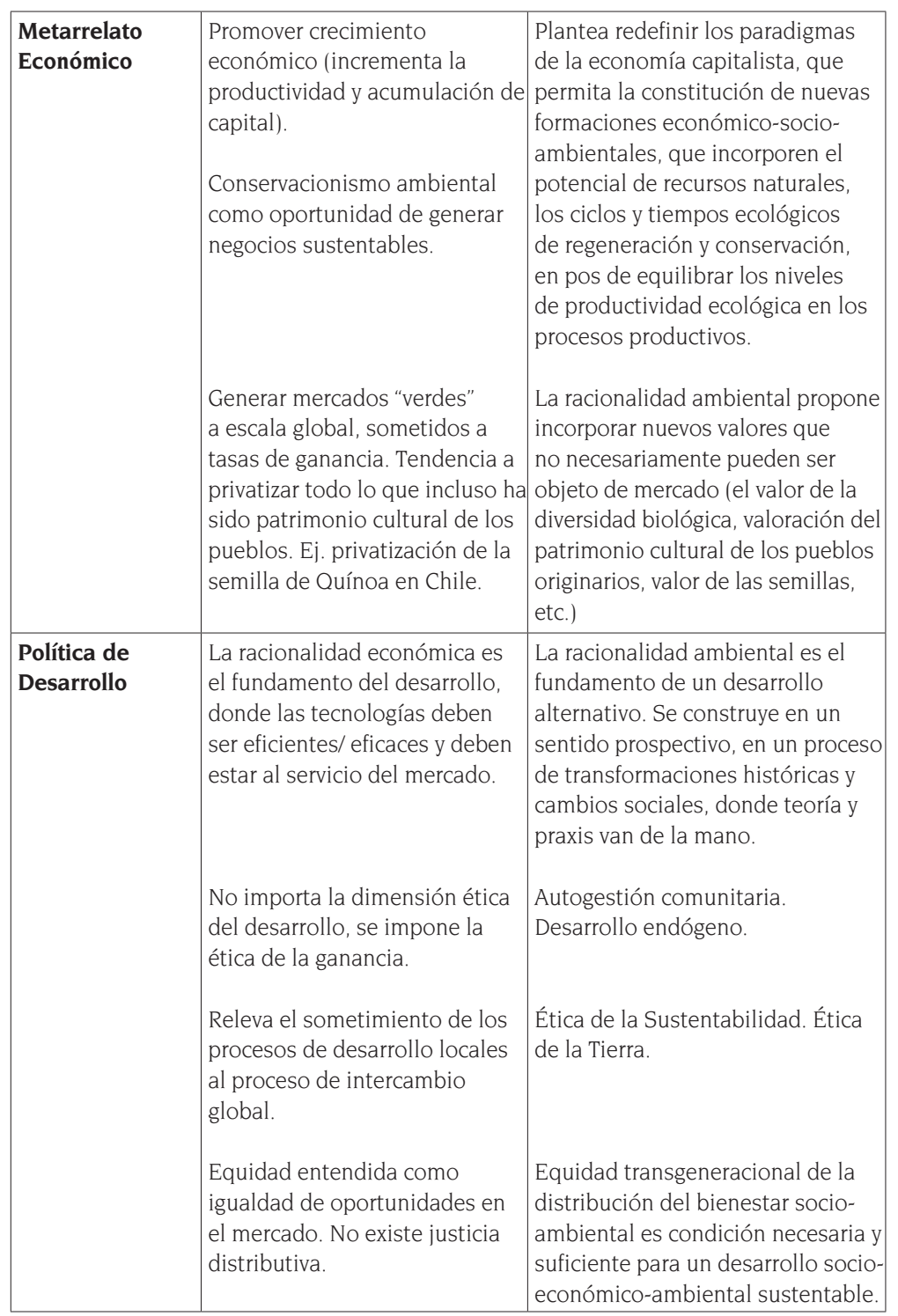

Del cuadro anterior se puede concluir que en el campo del saber ambiental coexisten los valores con los conocimientos y un conjunto de saberes prácticos y estratégicos en el campo de la acción política y el poder, así como la existencia de los recursos tecnológicos y/o técnicos aplicados a los procesos ambientales, que determinan el uso y distribución social de los bienes o servicios ambientales y las prácticas de transformación productiva y modificación de comportamientos ambientales. Se opta por este 
concepto de "saber" más que por "el de "conocimiento", tomando la distinción que hiciera Foucault (1979), el cual plantea que el saber es el proceso a través del cual el sujeto se encuentra modificado por lo que conoce, o mejor dicho, por el trabajo realizado para conocer, es lo que permite la modificación del sujeto y la construcción del objeto (es un concepto transformador, sujeto y objeto implicados en el proceso). Por su parte, el conocimiento es el proceso que permite la multiplicación de los objetos cognoscibles, la comprensión de su racionalidad; sin embargo, el sujeto que hace la investigación permanece siempre igual, no se implica (separación entre sujeto cognoscente y objeto).

Siguiendo a Enrique Left (2001) las ciencias sociales actuales no están a la altura de la contingencia actual, así como las autoridades políticas que tienen en sus manos el gobierno mundial y nacional no han dado muestras de voluntad política para revertir el proceso de muerte entrópica de la naturaleza; están más preocupados de hacer de la crisis ecológica un nuevo mercado y un nicho atractivo de negocios en vez de proponer nuevas estrategias de minimización de impactos negativos para la biosfera y la tierra. Un ejemplo chileno que ratifica lo anteriormente expuesto es la existencia de la empresa "Patagonia Sur" en Coyhaique, que tiene tres áreas de negocios: compensaciones de carbono, un servicio de eco-corretaje y un club de membresía. Los inversionistas pagan 350 mil dólares por acción (un poco más de 170 millones de pesos), poseen los activos y la totalidad de los flujos provistos por el negocio (San Cristóbal, 2012).

Si bien la apropiación de la naturaleza por parte del capital podemos identificarla como contradicción principal a resolver en el Chile de hoy, también es extensivo a escala planetaria. Tradicionalmente, "el marxismo se enfocó en la contradicción capitaltrabajo y no atendió a la relación capital-naturaleza más que de manera fragmentaria y aisladamente. Sin embargo, la acelerada expansión de la formación social capitalista a escala planetaria en las últimas décadas intensifica y renueva los procesos de apropiación privada y mercantilización de la naturaleza que Marx ubicara en una etapa originaria del capitalismo" (Sabbatella \& Tagliavini; 2012:17). Aun así, Marx intuyó el proceso por el cual el capitalismo avanzaba en la explotación de la tierra a escala mundial con el objeto de reproducirse cuantitativa y cualitativamente a escala planetaria; sus planteamientos nos hacen sentido hoy, al observar las pretensiones hegemónicas de la reproducción global del capitalismo neoliberal. 
La apropiación de la fuerza de trabajo por parte del capital que impulsó el modelo Estado-céntrico industrializador sigue vigente a escala global y local; de igual manera, los procesos de apropiación de los recursos naturales que sufren los países pobres, por parte de los países desarrollados, para sostener sus procesos productivos y acumulación a escala global. Sabemos que el consumo del norte se realiza a expensas de los recursos producidos por los países del sur. Esto ha ido generando una deuda y huella ecológica, que es traspasada a los países del sur, incluso a las generaciones que están por nacer. El hiper consumo de los países desarrollados es lo que ha hecho tomar conciencia -tanto en los movimientos ambientalistas del norte como los movimientos pro justicia ambiental en el sur-, sobre los límites ecológicos de nuestro ecosistema global, llegando incluso a límites peligrosos que sobrepasan con creces lo ocurrido en siglos anteriores. Hoy es mayor la injusticia ambiental, porque se imponen riesgos ambientales desproporcionados a las poblaciones más empobrecidas del planeta y a escala nacional, existiendo una imposición desigual de daños ambientales. Esta realidad que se nos presenta multi-problemática, debemos analizarla con una mirada multi-dialéctica, puesto que existe una relación dinámica entre capital - trabajo - naturaleza, que definiremos a continuación.

Las categorías "capital" y "trabajo" involucran relaciones existentes entre la "naturaleza" y el orden social, entendiendo estos tres componentes en constante influencia recíproca y coevolución histórica. Marx planteaba que "la naturaleza es la primera fuente de todos los medios y los objetos de trabajo, es decir la vía de entrada a la relación con la actividad humana" (Schmidt, 2012:8).

Por ello, Marx entendía la mercancía no como un objeto sino como una relación social, la cual puede existir en ciertas condiciones históricas. Esa forma social es una relación entre individuos; uno que vende su fuerza de trabajo (obreros) al capitalista (posee medios de producción y recursos financieros) lo que le otorga el poder de comprar dicha mercancía (fuerza de trabajo) para generar procesos de acumulación a escala ampliada y obtener mayores ganancias o plusvalía.

La noción de "capital" es una determinada relación social de producción, correspondiente a una determinada formación histórica de la sociedad, que se corporiza en una cosa material y le infunde un carácter social específico. Marx (1970) definió al 
Capital en 1898 como el conjunto de los medios de producción convertidos en capital y definidos hoy como el conjunto de los medios de producción monopolizados por una determinada parte de la sociedad, los productos y condiciones de su ejercicio a escala nacional y global. Hoy es el capital golondrina el que transita a través de los flujos del mercado global. Los grupos económicos nacionales no colocan "los huevos" sólo a nivel interno, sino que invierten en otros países que les den garantías de aumentar sus ganancias, optando por aquellos donde existen menores restricciones tributarias, mano de obra barata, materias primas de menor costo y mayor flexibilidad laboral.

Respecto a la categoría "trabajo", es la actividad con la cual el ser humano se apropia de su entorno y lo transforma en valores de uso, para satisfacer sus necesidades básicas. En el proceso de trabajo intervienen no sólo el trabajo humano, sino también el objeto sobre el cual se realiza y los medios de trabajo, ambos brindados por la naturaleza.

Si bien el "trabajo" es un bien que escasea hoy, no se podría afirmar que en Chile se dio paso a una sociedad post material, lo que es negado por el surgimiento y desarrollo de numerosos movimientos ciudadanos y populares, que hoy reivindican derechos económicos, sociales y ambientales, cuya defensa ciudadana re-instala nuevamente en el imaginario colectivo nacional la idea de su exigibilidad.

En relación al concepto de Naturaleza, Marx (1844) la había esbozado en 1844 en los Manuscritos Económico -Filosóficos al dar cuenta de la naturaleza: "La naturaleza es el cuerpo inorgánico del hombre, es decir, la naturaleza en cuanto no es ella misma el cuerpo humano. El hombre vive de la naturaleza; esto quiere decir que la naturaleza es su cuerpo, con el que debe permanecer en un proceso continuo, a fin de no perecer. El hecho de que la vida física y espiritual del hombre depende de la naturaleza no significa otra cosa sino que la naturaleza se relaciona consigo misma, ya que el hombre es parte de la naturaleza" (Marx, 1844:55)

Continuando con Marx, éste nos plantea que la productividad del trabajo y la producción de plusvalía dependerán de un conjunto de condiciones naturales, condiciones que se refieren a la naturaleza misma del ser humano y a la naturaleza circundante (Marx, 1970). Para el autor, "las condiciones de la naturaleza exterior se agrupan económicamente en dos grandes categorías: 
riqueza natural de medios de vida, o sea, fecundidad del suelo, riqueza pesquera, etc., y riqueza natural de medios de trabajo, saltos de agua, ríos navegables, madera, metales, carbón, etc." (Sabbatella E Tagliavini, 2012:1). Agrega Sabbatella (2012) que Marx no sólo dio cuenta de que el problema no era la unidad del hombre con la naturaleza, sino más bien lo que necesitaba explicación era la separación que se había establecido entre ser humano y naturaleza, y esta separación es de carácter histórico y es la base sobre la que se asienta la relación capital-trabajo, y por otra parte, el modo de producción capitalista es la causa fundamental de la separación campo - ciudad, dando como consecuencia concentración de la propiedad de la tierra en los campos y despoblamiento rural, y en las ciudades, polución, depredación y hacinamiento.

En este sentido, el paradigma marxista nos ofrece ventajas para analizar las condiciones materiales-productivas de la actual sociedad capitalista, que nos hace develar con mayor nitidez el rol que ocupa la relación natural ser humano - naturaleza en los procesos productivos. "Es el hombre quien pone su fuerza de trabajo, bajo una forma útil para su propia vida, las materias que la naturaleza le brinda" (Marx, 1970:15), dando cuenta de la naturaleza como fuente de valor de uso y valor de cambio. Del párrafo anterior se puede extraer la idea de que Marx reconoció la existencia natural del ser humano, previa a su condición social, y por lo tanto, constata cómo el trabajo humano transforma la naturaleza, y a su vez, la naturaleza transforma al ser humano. De allí la tesis de que el capital no sólo enajena al ser humano de su trabajo como un particular, lo aliena del ser genérico, pero al mismo tiempo, lo aliena de su relación con la naturaleza. Al mismo tiempo, la naturaleza, es despojada de su ciclo natural, es cosificada y transformada en mercancía.

Siguiendo a Rosa Luxemburgo (1913), ya en 1913 planteó con mucha claridad, cómo el capital no puede desarrollarse sin los medios de producción, la fuerza de trabajo del planeta entero y los tesoros naturales de los países pobres. Vale decir, el capitalismo desde sus orígenes ha tendido a la expansión espacial del capital. Dicha expansión sólo sería posible si se eliminan los límites y fronteras. Podemos interpretar esta tendencia mencionada por Luxemburgo como la globalización actual. La globalización se ha convertido en una realidad porque es la emanación real de las potencialidades inmanentes de la acumulación capitalista, lo que se reafirma en el párrafo siguiente "el movimiento de acumulación, 
necesita los tesoros naturales y las fuerzas de trabajo de toda la Tierra. Pero como éstas se encuentran, de hecho, en su gran mayoría, encadenadas a formas de producción pre capitalistas (este es el medio histórico de la acumulación de capital) surge de aquí el impulso irresistible del capital a apoderarse de aquellos territorios y sociedades" (Luxemburgo, 1913:4).

Finalmente, se podría plantear que el conjunto de categorías aportadas por el enfoque marxista ecológico, nos permiten ampliar la noción de "Formación Económica Social (FES)", para comprender y analizar al capitalismo actual como una "Formación Económica Social-Ambiental" (FESA), cuya dinámica de apropiación asume una doble expresión; por una parte, es intensiva, puesto que procede a privilegiar el monocultivo, la producción intensiva, que acarrea graves problemas (deforestación, pobreza, degradación de recursos, migración socio-ambiental, etc.). Un ejemplo en Chile es la Industria Salmonera en Chiloé, puesto que Chile ocupa el $2^{\circ}$ lugar en exportación de salmones, que ha provocado severos impactos físicos, químicos, biológicos, de degradación ambiental en la Décima Región, contaminando lagos y mares.

Respecto a la segunda, la capacidad expansiva de dicho capital se refiere a la expansión de la lógica capitalista a escala global, aplicando la lógica de apropiación de los recursos naturales en los países pobres o en vías del desarrollo, en una dinámica destructiva de todas las dimensiones de la vida, socavando aceleradamente las condiciones que hacen posible la reproducción de los seres humanos y no-humanos, en los ecosistemas nacionales y globales.

\section{¿Cómo se configura un conflicto socio- ambiental?}

Siguiendo a Marcel Claude (1997) se entiende por conflicto socio-ambiental, aquel conjunto de tensiones que se producen por la existencia de posiciones o divergencias encontradas, a partir de intereses contrapuestos. La configuración del conflicto se expresa en un determinado escenario social, económico, político y ambiental, puesto que dicha problemática ambiental está indisolublemente unida a la problemática general de la cuestión eco-social. Por otra parte, el Instituto Nacional de Derechos Humanos no sólo define los conflictos socioambientales como disputas entre diversos actores: personas naturales, organizaciones, empresas privadas y/o el Estado, que 
se manifiestan a nivel público, sino agrega que dichos conflictos "también son susceptibles de demandas, por la afectación (o potencial afectación) de derechos humanos, derivada del acceso y uso de los recursos naturales, así como por los impactos sociales y/o ambientales que generan a las comunidades las actividades económicas" (INDH, 2012:2), lo cual resulta interesante desde un enfoque de derechos humanos.

Los factores categoriales que nos aporta Marcel Claude (1997) para definir un conflicto socio-ambiental son los siguientes:

a) La incompatibilidad de intereses contrapuestos, es un factor relevante en el origen del conflicto. Grupos sociales o comunidades urbanas o indígenas, amenazadas por impactos indeseables (ej.: contaminaciones, pérdida de aguas subterráneas) derivados de prácticas de otros grupos, en los cuales hay disputa por la apropiación de los mismos recursos o bienes ambientales, existiendo expectativas contradictorias frente a un mismo fenómeno.

b) El daño, se refiere a los impactos negativos que provoca un grupo específico hacia otro grupo o comunidad específica. Es un concepto subjetivo y relativo en cuanto a su apreciación. En la consideración del daño hay aspectos de cantidad e intensidad.

c) Un tercer factor relevante en la definición del conflicto lo constituye el desarrollo de proyectos o actividades que generan las posiciones de incompatibilidad entre los grupos afectados y los responsables de haber generado los daños.

d) Un cuarto factor son los agentes que participan del conflicto socio-ambiental. Estos son de tres tipos: los causantes del daño, los receptores del daño (los afectados) y los involucrados en el conflicto que asumen de agentes reguladores, quienes tienen la responsabilidad de vigilar el buen desempeño y la co-existencia de actividades diversas y contrapuestas, así como deben aplicar normas y leyes con el fin de permitir o prohibir las acciones que provocan el daño.

¿Qué actores se involucran en los conflictos socio-ambientales? Los actores ecologistas surgen a escala territorial - local y regional, como lo demuestra la prevalencia de 100 conflictos urbanos en la Región Metropolitana, entre los años 2006 y 2011 (SUR profesionales, 2011 ) y la concentración de conflictos ambientales en regiones desde Arica hasta la Patagonia, con una prevalencia 
en zonas más vulnerables y pobres, como lo ratifican varios estudios en Chile. La demanda ambiental se ha ido construyendo sobre la amenaza a la sobrevivencia. Los movimientos sociales de los pobres "son luchas por la supervivencia, y son por tanto movimientos ecologistas [...] en cuanto sus objetivos son las necesidades ecológicas para la vida" (Martínez, 1990:16), con una excepción en Chile, como lo es el movimiento ciudadano policlasista que surgió en junio del año 2011 en la Patagonia, quienes se organizaron en contra del megaproyecto Hidroeléctrico Hidroaysén, primando los intereses regionales.

La urdiembre neoliberal ha sido difícil de roer en estos últimos veintidós años. Actualmente, algunos movimientos ecologistas y/o ambientales han criticado la ley $N^{\circ} 19.300$ como insuficiente, puesto "que curiosamente dejaba en manos de las empresas inversionistas los Estudios de Impactos Ambientales (EIA), quedando facultado por ley que los gatos cuidaran la carnicería" (Claude, 1997:156). Actualmente, la nueva ley № 20.600 (28/junio/2012), que creó los Tribunales Ambientales, entidades sujetas a la Superintendencia del Medio Ambiente, tienen como función resolver las controversias medioambientales que surjan en procesos de evaluación ambiental, ya sea mientras se está evaluando o después que se apruebe un proyecto, acogiendo reclamos, fiscalizando sanciones, entre otras funciones. Sin embargo, cuando una persona o una comunidad experimenta la vulneración de su derecho a vivir en un medio ambiente libre de contaminación, que es un derecho de ciudadanía, eso se resuelve en la justicia ordinaria y no es materia de los Tribunales Ambientales. Esto ha dado pie a diversos cuestionamientos respecto a la seguridad y eficacia que tendrán estas entidades en la solución efectiva de los conflictos ambientales y en la aplicación de la justicia ambiental.

\section{A modo de conclusión: ¿Qué desafíos le demanda la cuestión eco-social a las profesiones de las ciencias sociales?}

Un primer desafío, es la incorporación de la dimensión ambiental en los paradigmas del conocimiento y del desarrollo, en los contenidos curriculares. Estos deben ser parte de una política de investigación científica y de formación ambiental en las Universidades, que faciliten la producción de conocimiento en las ciencias sociales (incluyendo al Trabajo Social), contribuyendo 
de tal manera a la comprensión de la cuestión eco-social actual y a la promoción del debate contemporáneo.

Un segundo desafío dice relación con impulsar prácticas de intervención y/o de educación ambiental, que tengan como ejes de acción la promoción de procesos de ciudadanización socioambiental, difundiendo los derechos sociales y ambientales, así como también la puesta en práctica del ejercicio de dichos derechos a través de acciones colectivas que demanden su exigibilidad, protección y construcción de nuevos derechos en este campo de ciudadanía.

Un tercer desafío es difundir y promover los valores de la ética de la sustentabilidad en las distintas disciplinas, con el objeto de construir una racionalidad ambiental que garantice de manera universal los bienes sociales y ambientales comunes, cuyo horizonte civilizatorio esté orientado hacia una economía a escala humana y una democracia sustantiva al servicio del bienestar social y ambiental que garantice una vida de calidad a todas y todos los chilenos/as.

"La cuestión ambiental es una problemática eminentemente social, sin embargo las ciencias sociales no han transformado sus conceptos, métodos y paradigmas teóricos para abordar las relaciones entre procesos sociales y los cambios ambientales emergentes" (Leff, 2001:57).

\section{Bibliografía}

Aquín, N. (2006). ¿Una nueva cuestión social? Revista Perspectivas 16, 7-14. Disponible en http://www.ucsh.cl/Uas/ opensite_20080425121026.asp

Claude, M. (1997). Una vez más la Miseria. ¿Es Chile un país sustentable? (Colección Sin Norte). Santiago de Chile: LOM.

Esping-Andersen, G. (1993). Los Tres mundos del Estado del Bienestar. Disponible en http://es.scribd.com/ doc/127902225/GOSTA-ESPING-ANDERSENLos-Tres-Mundos-Del-Estado-de-Bienestar1993.

Foucault, M. (1979). La Arqueología del Saber. España: Editorial Siglo XXI.

Figueroa, J.P. (2012). Los Nueve dueños del Mar Chileno. Disponible en http://ciperchile.cl/2012/01/25/los-duenosdel-mar-chileno/ (20 de Mayo 2013). 
Folchi, M. (2001). Conflictos de contenido ambiental y ecologismo de los pobres: no siempre pobres, ni siempre ecologistas. Ecología Política, 22. Disponible en http://www.captura.uchile.cl/handle/2250/5791

INDH, Instituto de Derechos Humanos. (2012). Mapa de conflictos socio-ambientales en Chile. Disponible en http://www.indh.cl/mapa-de-conflictossocioambiental es-en-chile

Larraín, S. y Poo, P. (2010). Conflictos por el Agua en Chile. Entre los Derechos Humanos y las reglas del Mercado. Disponible en http://cl.boell.org/downloads/05_Conflictos_ por_el_agua_chile.pdf

Left, E. (2001). Ciencias Sociales y formación ambiental. Madrid: Editorial Gedisa.

Luxemburgo, R. (1913). "La Reproducción del capital y su medio ambiente". En: La acumulación del Capital. Disponible en http://www.grupgerminal. org/?q=node/450

Marx, C. (1844). Los Manuscritos Económicos y Filosóficos. El Salario. Disponible en www.google.cl/\#q=primer+manu scrito+de+marx+pdf

Marx, C. (1970). El Proceso de producción del Capital. Sección 7 Proceso De Acumulación del Capital. En Autor, El Capital. Tomo I. España: Siglo XXI Editores.

Martínez, J. (1990). La interpretación ecologista de la historia socioeconómica: ejemplos de la región andina. Revista Estudios Regionales 26, 29-47. Disponible en http://www.revistaestudiosregionales.com/pdfs/ pdf305.pdf

Quiroga, R. (2003). Comercio, Inversiones y sustentabilidad: El caso de Chile. Santiago, Chile: LOM Ediciones.

Sabbatella I; Tagliavini, D. (2012). La expansión capitalista sobre la Tierra en todas las direcciones. Aportes del Marxismo Ecológico. Revista Theomai ( $\left.\mathrm{N}^{\circ} 26\right)$. Disponible en http://revista- theomai.unq. edu.ar/NUMERO\%2026/Sabbatella\%20y\%20 Tagliavini\%20-\%20Marxismo\%20ecológico.pdf

San Cristóbal, M. (2012). El negocio de las tierras protegidas en Chile. Periódico El Ciudadano, 5 de marzo 2012. Disponible en http://www.resumen. cl/index.php?option=com_contentEview $=$ articleEid=5341:el-negocio-de-las-tierrasprotegidas-en- chileEcatid=16:ecologia\&Item $\mathrm{id}=60$ 
Schmidt, A. (2012). EL Concepto de Naturaleza en Marx. España: Editorial Siglo XXI.

SUR, Corporación de Estudios Sociales y Educación. (2013). Mapas de conflictos urbanos de Santiago. Disponible en http://mapadeconflictos.sitiosur.cl/indexl php 